\title{
Modelling sensorial and nutritional changes to better define quality and shelf life of fresh-cut melons
}

\author{
Maria Luisa Amodio, Antonio Derossi, Giancarlo Colelli \\ Department of Science of Agriculture, Food and Environment, University of Foggia, Italy
}

\begin{abstract}
The shelf life of fresh-cut produce is mostly determined by evaluating the external appearance since this is the major factor affecting consumer choice at the moment of purchase. The aim of this study was to investigate the degradation kinetics of the major quality attributes in order to better define the shelf life of fresh-cut melons. Melon pieces were stored for eight days in air at $5^{\circ} \mathrm{C}$. Sensorial and physical attributes including colour, external appearance, aroma, translucency, firmness, and chemical constituents, such as soluble solids, fructose, vitamin $\mathrm{C}$, and phenolic content, along with antioxidant activity were monitored. Attributes showing significant changes over time were used to test conventional kinetic models of zero and first order, and Weibullian models. The Weibullian model was the most accurate to describe changes in appearance score, translucency, aroma, firmness and vitamin $\mathrm{C}$ (with a regression coefficient always higher than 0.956), while the other parameters could not be predicted with such accuracy by any of the tested models. Vitamin C showed the lowest kinetic rate among the model parameters, even though at the limit of marketability (appearance score 3), estimated at five days, a loss of $37 \%$ of its initial content was observed compared to the fresh-cut product, indicating a much lower nutritional value. After five days, the aroma score was already 2.2 , suggesting that this quality attribute, together with the vitamin $\mathrm{C}$ content, should be taken into account
\end{abstract}

Correspondence: Maria Luisa Amodio, Department of Science of Agriculture, Food and Environment, University of Foggia, Italy.

Tel. +39.0881.589406.

E-mail address: m.amodio@unifg.it

Key words: Weibull distribution, fresh-cut fruits, melons, shelf life, mathematical modelling.

Acknowledgements: the research leading to these results has received funding from the European Union Seventh Framework Programme (FP7/20072013) under grant agreement no. 289719 (QUAFETY Project).

Received for publication: 21 February 2013.

Accepted for publication: 22 May 2013.

(C) Copyright M.L. Amodio et al., 2013

Licensee PAGEPress, Italy

Journal of Agricultural Engineering 2013; XLIV:e6

doi:10.4081/jae.2013.e6

This article is distributed under the terms of the Creative Commons Attribution Noncommercial License (by-nc 3.0) which permits any noncommercial use, distribution, and reproduction in any medium, provided the original author(s) and source are credited. when assessing shelf life of fresh-cut melons. In addition, logistical models were used to fit the percentage of rejected samples on the basis of non-marketability and non-edibility (appearance score $<3$ and $<2$, respectively). For both parameters, correlations higher than 0.999 were found at $\mathrm{P}<0.0001$; for each mean score this model helps to understand the distribution of the samples among marketable, nonmarketable, and non-edible products.

\section{Introduction}

Over the last 20 years, there has been an enormous increase in the interest shown by consumers in segments of fresh-cut fruit and vegetables. This success is the result of their convenience as ready-to-eat products and of the health benefits associated with their consumption (Martin et al., 2002; Oms-Oliu et al., 2009; Sothornvit and Kiatchanapaibul, 2009). Also, the organoleptic properties of these products means their quality remains close to that of fresh, uncut produce. In terms of health benefits, fresh-cut commodities increase the intake of several nutrients such as minerals, vitamin C, vitamin A and thiamin, as well as chemical compounds with functional properties such as fibre, carotenoids, flavonoids and antioxidants (Gil et al., 2006). In this way, a diet rich in fresh-cut fruit may help prevent cancer and cardiovascular diseases (Ames, 1983).

Among different types of fruit, the production of fresh-cut melon is of great interest for its appreciated sensorial attributes and for the difficulties of its direct consumption due to its large dimension and for the preparation needed before eating (Amaro et al., 2012). It is well known that fresh-cut processing, with the associated wounding of the vegetable tissue, induces physiological disorders generated by degradation reactions, reducing the shelf life of these products. Among these, browning, a dry appearance, flaccidity, and microbial growth are the most important aspects of visual quality degradation (Brecht, 1995). Losses of nutrients and aroma may also be accelerated when plant tissues are wounded (Klein, 1987; Bett et al., 2001). Browning due to oxidation of phenols, for instance, may reduce nutrient content (Vámos-Vigyázó, 1981).

Among the external variables affecting quality, temperature is a key factor for the overall degradation of fresh-cut fruit in that it controls all reaction rates, such as vitamin $\mathrm{C}$ degradation (Davey et al., 2000), browning (Manso et al., 2001), microbial growth (OdriozolaSerrano et al., 2009), etc. On these bases, the modelling and the correlation of the changes in visual appearance with the nutritional compounds is one of the most interesting research challenges which will help to better define shelf-life of fresh-cut produce. This is also of crucial importance for the design and optimisation of the supply chain (Dabbene et al., 2008; Jacxsens et al., 2010). For example, as reported by Jacxsens et al. (2010), globalisation has meant that a simple supply chain moves towards a global logistical network and meets many unpredictable conditions on the way that have a strong impact on the 
safety and quality of fresh products. An optimum logistical network should guarantee the high quality of fresh-cut fruit and vegetables while also minimising costs and maximising sustainability indicators. With these considerations in mind, the correct mathematical modelling of degradation reactions of fresh-cut products is essential in order to obtain the best logistical network design. However, the use of timedependent safety/quality information in the design of distribution systems has rarely been used (Jacxsens et al., 2010).

In general, quality degradation reactions are modelled by the conventional zero, first, or second order kinetics (Labuza, 1982; Tauokis et al., 1997; Zanoni et al., 2005; Nisha et al., 2005; Giannakorou and Tauokis, 2003; Rekha Nisha et al., 2004; Rodrigo et al., 2007; Sothornvit and Kiatchanapaibul, 2009). Very often, after the estimation of a kinetic constant, the well-known Arrhenius equation is traditionally used to estimate rate constant at any temperature value by which it is possible to obtain a correct shelf-life prediction. Nevertheless, this methodology has been subject to some criticism (Corradini and Peleg, 2004a, 2004b; Corradini and Peleg, 2006; Corradini and Peleg, 2007) related to the fact that, in some cases, the deterioration rate is not only a function of temperature but also of time. Therefore, other empirical or mechanistic models have been proposed (Peleg, 1988; Cunha et al., 2001; Marabi et al., 2003; Corradini and Peleg, 2007). Among these, the Weibull model is the cumulative form of the Weibull distribution function that is extensively used in engineering to describe time to failure in electronic or mechanical systems when submitted to external stress. In the same way, degradation reactions of foods may be considered probabilistic phenomena during which two states co-exist. These models fitted well with several food degradation reactions, such as microbial growth (van Boekel, 2002; Corradini and Peleg, 2004a; Corradini and Peleg, 2007), antioxidant changes (Oms-Oliu et al., 2009), vitamin C degradation in frozen spinach or green peas (Corradini and Peleg, 2007), riboflavin degradation during thermal treatments (Corradini and Peleg, 2006), browning of orange juice (Manso et al., 2001). However, few examples are reported in literature of the use of the Weibull model to study degradation reactions of fresh-cut fruit (Oms-Oliu et al., 2009; OdriozololaSerrano et al., 2009). This paper aims: i) to study the kinetics of the most important sensorial and chemical changes in fresh-cut melons by comparing the conventional zero and first order kinetics with the Weibull model; ii) to obtain a better definition of the quality of sample by correlating sensorial and chemical changes during storage; and, finally, iii) to estimate the shelf life of fresh-cut melon samples.

\section{Materials and methods}

Thirty Cantaloupe melons from an orchard in the province of Foggia, Italy, were sanitised with $0.01 \%$ solution of free chlorine, peeled, and cut into cubes soon after harvest (i.e. firm-ripe stage with a clear abscission from the vine applying light pressure). Melon pieces were randomly mixed and divided into 60 plastic containers wrapped with macro-perforated PET bags and stored at $5^{\circ} \mathrm{C}$. At start of study and at each storage time point (after 1, 2, 3, 7 and 8 days) 10 containers, representing 10 replicates, were used for quality determinations. On fresh samples, colour, general appearance, soluble solids (degree Brix), titratable acidity (percentage of citric acid) and vitamin C (mg/100 g) were assessed. In addition, 5 pieces/replicates were frozen for further extraction for both total phenolics (mg/100 g) and antioxidant activity (mg/100 g), and individual sugars and organic acid composition, as described below.

\section{Physical and sensorial attributes}

A panel of 4 laboratory experts subjectively assessed the samples for appearance, aroma, translucency, acidity, sweetness, texture and overall quality, using a 1-5 scale where 5 =typical attribute, very intense, without defects; $4=$ intense, slight defects; $3=$ fair, acceptable defects; 2 =poor, major defects; 1 =inedible, very poor, strong defects (Amodio et al., 2007). Generally, score 3 was considered to be the limit of marketability (with the exception of firmness since samples that are too firm may not be accepted by the consumers) and 2 as the limit of not being edible.

Colour was measured using a Spectral scanner (DV SRL, Roma, Italy) equipped with a Spectral Imaging spectrometer V10 type (400$1000 \mathrm{~nm}, 25 \mu \mathrm{m}$ slit, resolution $5 \mathrm{~nm}$ ). One scan per replicate was acquired at a speed of $3 \mathrm{~mm} / \mathrm{s}$ in a dark room with a stabilised halogen light source $(150 \mathrm{~W})$. On the stored hyperspectral images a region of interest was selected for each cube (a square of $1 \mathrm{~cm}^{2}$ ). The instrument software automatically measured the mean value of $\mathrm{L}^{*}, \mathrm{a}^{*}, \mathrm{~b}^{*}$ of the selected region in the CIE $\mathrm{L}^{*} \mathrm{a}^{*} \mathrm{~b}^{*}$ scale, elaborating the reflectance value to each pixel.

Firmness was measured as the force at the rupture point $(\mathrm{N})$ of a cube of $1 \mathrm{~cm}$ per side, pressed between 2 plates applying an increasing load at a speed of $30 \mathrm{~mm}^{*} \mathrm{~min}^{-1}$ with an Instron Universal Testing Machine (model 3340) [Instron - Div. di ITW Test and Measurement Italia S.r.l., Trezzano sul Naviglio (MI), Italy].

\section{Chemical analysis}

Fresh pieces were squeezed and the juice used for titration with $0.1 \mathrm{~N} \mathrm{NaOH}$ to $\mathrm{pH} 8.1$ to measure acidity expressed as percentage of citric acid, and for the assessment of soluble solid content with a digital refractometer (Atago, PR-32, Tokyo, Japan).

Sugar and organic acid contents were analysed using an high-performance liquid chromatography system (Agilent Technologies 1200 Series, Waldbronn, Germany) equipped with Refractive and DAD detectors. Separation of acids was determined according to the method of Sáiz-Abajo et al. (2005) while sugars were separated on an Alltima Amino column $(250 \times 4.6 \mathrm{~mm} ; 5 \mathrm{~m}$ particle size; Alltech, Deerfield, IL, USA), with a flow of $0.8 \mathrm{~mL}$ min- 1 of acetonitrile:water (75:25). Sugars and acids were expressed as mg per $100 \mathrm{~g}$ fresh weight $(\mathrm{mg} / 100 \mathrm{~g} \mathrm{fw})$.

The same extraction was conducted for both total phenols and antioxidant activity analyses. Total phenols were determined according to the method of Singleton and Rossi (1965), while the antioxidant assay was performed following the procedure described by BrandWilliams et al. (1995).

Ascorbic acid and dehydroascorbic acid contents were determined as described by Zapata and Dufour (1992).

\section{Statistical analysis}

A one-way analysis of variance (ANOVA) was performed for each quality attribute in order to evaluate the significant differences of each individual quality index as a function of time.

\section{Mathematical modelling}

\section{Zero and first order kinetic models}

Zero and first order kinetics, traditionally used to describe degradation reactions in foods, may be generally written as (Giannakourou and Taoukis, 2003; Polydera et al., 2005; Zanoni et al., 2005; Nisha et al., 2005):

$$
\frac{d C(t)}{d t}=-k C^{m}
$$


where

$C_{(t)}$ is the concentration of the quality index at the time $t, k$ is the rate constant, and $m$ is the kinetic order of the equation. The equation may be integrated easily obtaining the well-known decay functions. In particular, zero order kinetic model $(m=0)$ is written as $C_{(t)}=C_{0}-k t$ whereas first kinetic order $(m=1)$ is $C(t)=C_{0} e^{-k t}$.

\section{Weibull model}

To characterise the kinetic of sensorial and chemical changes of melon samples, experimental data were fitted with the Weibull model. In particular, as reported by van Boekel (2002), the cumulative distribution of the Weibull distribution function is given by Equation 2:

$$
S(t)=\exp \left[-\left(\frac{t}{\alpha}\right)^{\beta}\right]
$$

where

$\mathrm{S}$ is the independent variables, $t$ is the time of the process, $\alpha$ days) is the scale factor, and $\beta$ (dimensionless) is the shape factor. In particular, Equation 2 may be rewritten in the following form:

$$
C(t)=C_{0} \exp \left[-\left(\frac{t}{\alpha}\right)^{\beta}\right]
$$

where

$C(t)$ and $C_{0}$, respectively, are the values of each studied quality index as a function of time and at initial condition. In Eq. 3, the constants $\alpha$ and $\beta$ were estimated, while the experimental value at the start of storage was used for $\mathrm{C}_{0}$. Moreover, as reported by Corradini and Peleg (2006), since the slope of the survival curve has rate units, Eq. 1 may be considered as the kinetic empirical model. In this way, the reciprocal of scale factor $1 / \alpha$ may be considered the rate constant of the process obtaining the Weibull models used by several authors (Oms-Oliu et al., 2009; Corradini and Peleg, 2004a; Corradini et al., 2005). The goodness of fit was evaluated by the correlation coefficient (r), the sum of square error, and the root mean square error (RMSE). Moreover, the kinetic parameters were compared by the confidence interval calculated at $95 \%$ of probability.

\section{Logistical model}

The fraction of non-marketable and non-edible samples was calculated as $\mathrm{F}=\mathrm{N} / \mathrm{N}_{\text {tot }}$, where $\mathrm{N}$ is the number of packages containing the samples at which the panel of experts assigned an appearance score of less than 3 and less than 2 , while $\mathrm{N}_{\text {tot }}$ is the total number of samples. Once the values had been calculated for each storage time, they were fitted by the following logistical model:

$$
F=\frac{C}{1+A e^{(-B X)}}
$$

where

$X$ (dimensionless) is the average appearance score while $C, A$, and $B$ are fitting parameters (dimensionless). The goodness of fit was calculated as previously reported.

\section{Results and discussion}

Table 1 shows the mean values for chemical and sensorial attributes of fresh-cut melons at the time of cutting. As expected, the panel of experts gave an appearance score of $4.85 \pm 0.2$ indicating the absence of any defects on fresh samples. The same consideration may be made for translucency, that obtained the maximum score (5.0), indicating no translucent areas had been observed. For aroma, texture and sweetness, the mean scores were $3.60 \pm 1.10,3.77 \pm 0.80$, and $3.12 \pm 1.00$, respectively, which were significantly lower than the maximum 5.0 on the scale, demonstrating the variability of the samples in terms of sweetness and aroma, and a typical texture for consumption (higher values would have indicated samples were too firm to be eaten). An ANOVA was performed

Table 1. Mean values for sensorial and chemical attributes of fresh melon at the time of cutting.

\begin{tabular}{lc} 
& \\
Sensorial attributes & Mean value \pm standard deviation \\
Appearance score & $4.85 \pm 0.24$ \\
Aroma score & $3.60 \pm 1.1$ \\
Texture score & $3.77 \pm 0.8$ \\
Translucency score & $5.0 \pm 0.0$ \\
Sweetness score & $3.12 \pm 1.0$ \\
Overall quality score & $3.62 \pm 0.8$ \\
Physical attributes & \\
Firmness (N) & $27.64 \pm 13.6$ \\
L* value & $83.52 \pm 2.35$ \\
a $^{*}$ value & $14.54 \pm 3.02$ \\
b* value & $51.45 \pm 2.23$ \\
Chroma & $53.86 \pm 2.67$ \\
Hue angle & $51.73 \pm 2.56$ \\
Compositional attributes & \\
Vitamin C (mg/100 g) & $17.93 \pm 3.78$ \\
Phenol content & $18.07 \pm 2.5$ \\
Antioxidant capacity (mg TE/100 g w.b.) & $18.70 \pm 4.25$ \\
Titrable acidity & $1.45 \pm 1.0$ \\
Fructose (g/100 w.b.) & $1.14 \pm 0.25$ \\
Glucose (g/100 g w.b.) & $0.83 \pm 0.117$ \\
Sucrose (g/100 w.b.) & $1.52 \pm 0.520$ \\
Soluble solids ( ${ }^{\circ}$ Bx) & $8.8 \pm 1.27$ \\
\hline
\end{tabular}


(Table 2) to evaluate whether there was a significant variation in the quality indexes during storage, and, therefore, if significant variations were observed over time. There were significant variations in sensorial and physical attributes, appearance score, $\mathrm{b}^{*}$ value, $\mathrm{L}^{*}$ value, chroma, hue angle, aroma score, firmness and translucency score during the eight days of storage. Other sensorial attributes were not included in the analysis due to the low number of observations, since the panel of experts considered the melon samples inedible before the end of the eight days of storage. As far as changes in chemical attributes are concerned, significant variations were observed for vitamin $\mathrm{C}$, titratable acidity and fructose content, whereas the other quality indexes were not affected by the time of storage, showing $P$ values always greater than 0.112 (ANOVA). Quality attributes that showed significant changes over time were fitted by zero and first order kinetic models as well as by the
Weibull model (Eq. 3) (Table 3). Among all the parameters evaluated, appearance score, Vitamin C, aroma score, translucency score, and firmness showed values of correlation coefficients higher than 0.926 and RMSE values between 0.1546 and 1.1790 . The fitting of the remaining quality attributes is not reported since the regression coefficient was lower than 0.8. For the parameters reported, all models were, however, sufficiently accurate. A comparison of goodness of fit parameters among the models, for appearance score, vitamin C content, aroma and translucency scores, the Weibull model clearly showed correlation coefficients that were always higher than those obtained by using the conventional models. In particular, $r$ and RMSE values ranged between 0.956 and 0.990 and 0.1546 and 0.9518 , respectively, indicating the higher ability of the Weibull model to fit experimental data. These results confirm the view that the conventional zero and first order kinetics have little flexibility for

Table 2. Analysis of variance (ANOVA) of sensorial and chemical indexes of fresh-cut melons cubes. Effect of storage time.

\begin{tabular}{|c|c|c|c|c|c|}
\hline & SS & df & MS & $F$ & $\mathbf{P}$ \\
\hline $\begin{array}{l}\text { Sensorial attributes } \\
\text { Appearance score } \\
\text { Aroma score } \\
\text { Texture score } \\
\text { Translucency score }\end{array}$ & $\begin{array}{c}111.48 \\
21.33 \\
1.017 \\
33.03\end{array}$ & $\begin{array}{l}5 \\
5 \\
3 \\
5\end{array}$ & $\begin{array}{c}22.29 \\
4.26 \\
0.33 \\
6.60\end{array}$ & $\begin{array}{c}141.64 \\
5.31 \\
0.90 \\
18.7\end{array}$ & $\begin{array}{c}<0.001 \\
<0.001 \\
0.446 \\
<0.001\end{array}$ \\
\hline $\begin{array}{l}\text { Physical attributes } \\
\text { Firmness } \\
\mathrm{L}^{*} \text { value } \\
\mathrm{a}^{*} \text { value } \\
\mathrm{b}^{*} \text { value } \\
\text { Chroma (c) } \\
\text { Hue angle (h) }\end{array}$ & $\begin{array}{c}2429.66 \\
155.30 \\
36.75 \\
208.30 \\
196.40 \\
207.4\end{array}$ & $\begin{array}{l}5 \\
5 \\
5 \\
5 \\
5 \\
5\end{array}$ & $\begin{array}{c}485.93 \\
31.10 \\
7.35 \\
41.70 \\
39.30 \\
41.5\end{array}$ & $\begin{array}{l}4.94 \\
5.18 \\
1.57 \\
7.11 \\
6.22 \\
7.06\end{array}$ & $\begin{array}{l}<0.001 \\
<0.001 \\
0.183 \\
<0.001 \\
<0.001 \\
<0.001\end{array}$ \\
\hline $\begin{array}{l}\text { Compositional attribut } \\
\text { Vitamin C } \\
\text { Phenol contents } \\
\text { Antioxidant activity } \\
\text { Titrable acidity } \\
\text { Fructose content } \\
\text { Glucose content } \\
\text { Sucrose content } \\
\left.\text { Soluble solids ( }{ }^{\circ} \mathrm{Bx}\right)\end{array}$ & $\begin{array}{c}442.40 \\
85.69 \\
58.59 \\
22.59 \\
0.66 \\
0.20 \\
3.09 \\
8.49\end{array}$ & $\begin{array}{l}5 \\
5 \\
5 \\
5 \\
5 \\
5 \\
5 \\
5\end{array}$ & $\begin{array}{l}88.48 \\
17.14 \\
11.72 \\
4.51 \\
0.13 \\
0.04 \\
0.61 \\
1.70\end{array}$ & $\begin{array}{l}4.90 \\
1.16 \\
0.57 \\
6.12 \\
4.33 \\
1.70 \\
1.88 \\
0.97\end{array}$ & $\begin{array}{c}<0.001 \\
0.339 \\
0.718 \\
<0.001 \\
<0.001 \\
0.146 \\
0.112 \\
0.443\end{array}$ \\
\hline
\end{tabular}

SS, sum of squares; df, degree of freedom; MS, mean square; F, F-distribution.

Table 3. Goodness of fitting of zero and first kinetics and Weibull models used to estimate some quality index of fresh-cut melon samples.

$\begin{array}{lcccc}\text { Quality attribute } & \text { Model } & \text { Correlation coefficient }(r) & 0.6051 & \text { SSE } \\ \text { Appearance score } & \text { Zero order kinetic } & 0.972 & 1.17 & 0.518 \\ & \text { First order kinetic } & 0.946 & 0.335 & 0.3088 \\ & \text { Weibull } & 0.974 & 0.2694 & 0.4280 \\ \text { Aroma score } & \text { Zero order kinetic } & 0.933 & 0.2254 & 0.2896 \\ & \text { First order kinetic } & 0.947 & 0.0812 & 0.2594 \\ & \text { Weibull } & 0.956 & 0.1366 & 0.1426 \\ \text { Translucency score } & \text { Zero order kinetic } & 0.980 & 0.0717 & 0.1848 \\ & \text { First order kinetic } & 0.981 & 2.804 & 0.1546 \\ \text { Firmness } & \text { Weibull } & 0.990 & 5.563 & 3.43 \\ & \text { Zero order kinetic } & 0.994 & 0.8373 \\ \text { Vitamin C } & \text { First order kinetic } & 0.988 & 7.374 & 0.9260 \\ & \text { Weibull } & 0.992 & 5.416 & 1.3580 \\ \end{array}$

SSE, sum of square error; RMSE, root mean square error. 
providing a good estimation in different conditions. In fact, the results are in accordance with several authors (Manso et al., 2001; Rekha Nisha et al., 2004; Rodrigo et al., 2007; Sothornvit and Kiatchanapaibul, 2009; Oms-Oliu et al., 2009; Odriozola-Serrano et al., 2009). Oms-Oliu et al. (2009) obtained a correlation coefficient that was always over 0.976 and RMSE values below 1.002, fitting the changes in vitamin $\mathrm{C}$ content of fresh-cut melon samples stored between $5^{\circ} \mathrm{C}$ and $20^{\circ} \mathrm{C}$ with the Weibull model. The same authors showed a correlation coefficient always higher than 0.986 when the total phenolic content as a function of time was fitted. Always considering cut melons, Amodio et al. (2012) indicated that the first order kinetic model was the apparent order of the quality change regarding $\mathrm{L}^{*}, \mathrm{a}^{*}, \mathrm{~b}^{*}$, appearance score, fructose content, titratable acidity, vitamin $\mathrm{C}$, and phenol contents, but that it did not report regression coefficients. The results in Table 3 show that, in the case of firmness, the zero order kinetic model was found to be the best to estimate experimental data showing a correlation coefficient of 0.994 and a RMSE of 0.8373 . However, the use of the Weibull model provided a correlation coefficient of 0.992 and a RMSE of 0.9260 indicating its high ability also in fitting firmness data. On the basis of these results, the Weibull model was used to compare the degradation kinetics of each quality attribute. Table 4 shows the estimated parameter values for scale $(\alpha)$ and shape $(\beta)$ factors of the Weibull model for each quality attribute. In the case of the appearance score, $\alpha$ and $\beta$ values were 7.354 and 1.967 , respectively, and the confidence intervals showed the accuracy of the Weibull model in estimating the appearance score of melon samples as a function of time of storage. Also, vitamin $\mathrm{C}$ content showed the lower degradation rate (the higher $\alpha$ value), whereas firmness quickly degraded, as did appearance score that showed degradation rates of 0.1359 and $0.1166 \mathrm{~d}^{-1}$, respectively. Furthermore, it is worth noting the differences in the estimated shape factors that showed values ranging between a minimum of 0.6291 for vitamin $C$ and a maximum of 1.967 for the appearance score. As reported by van Boekel (2002), $\beta$ values over 1 lead to a downward concavity of the degradation curve, and this is the case of the degradation of appearance, translucency, and firmness scores, whereas $\beta$ values less than 1 , observed for vitamin $\mathrm{C}$ content and aroma degradation, result in an upward concavity.

Figure 1 shows the evolution of appearance score and the fit obtained by the Weibull model. During the first two days, as shown by ANOVA results $(\mathrm{P}>0.05)$, average values were approximately constant between 5 and 4.4 and the samples were highly appreciated by the panel of experts. Appearance score degradation rate substantially increased starting from Day 3. Moreover, it was estimated that the limits of marketability (score 3 ) and edibility (score 2) were reached after 5 and 6.9 days, respectively. However, since the general appearance scores are usually obtained by averaging the values to the samples assigned by the panel of experts, some authors studied the trend of the percentage of rejected samples calculating the fraction of consumers who answered $N o$ when they were asked if they would normally buy a package containing the samples (Ares et al., 2008). In our case, the fraction of rejected samples and the fits obtained by the logistical model were plotted versus the correspondent mean appearance scores (Figure 2) allowing us to determine the distribution among marketable, non-marketable and non-edible samples for each given score. As shown, the fits appeared to be practically indistinguishable from the experimental data indicating the accuracy of the model in predicting the fraction of packages considered as non-marketable and non-edible. In particular, in both cases, correlation coefficients of 0.999 and $\mathrm{P}<0.0001$ were observed (data not shown), e.g. in the case of the curve of edibility values of $100.36 \pm 0.801,-4.29 \pm 1.3$ and $0.0001 \pm 0.0001$, respectively, for the parameters A, B and C which, on the basis of the very low confidence interval, indicated the good estimation of the parameters. Also, studying the normal probability plot of the residuals it was possible to show the high ability of the logistical model to fit the experimental data (data not shown). These results confirm the finding of Ares et al. (2008) on fresh-cut lettuce samples. When the mean appearance score of 4 was reached, a fraction of approximately $5 \%$ of the packages were already considered non-marketable, while when an average appearance score of 3 was given, a fraction of $35.8 \%$ was considered under this limit (non-marketable) while a fraction of $4.8 \%$ was already considered non-edible. Also, it is easy to estimate that a sample fraction of $31 \%$ showed appearance scores between 2 and 3 . In the same way, by considering the curve of edibility, it was possible to observe that when the mean appearance score of 2 was reached, a sample fraction of $20 \%$ was judged to be still edible and a fraction of $13.5 \%$ was even considered marketable. Again, a sample fraction of $6.5 \%$ was judged by the panel of experts to be between the marketability and edibility limits. These results indicate how the mean appearance score value may be not very representative of all the samples, and that these indexes can be very useful when assessing the sensorial quality of a fresh product.

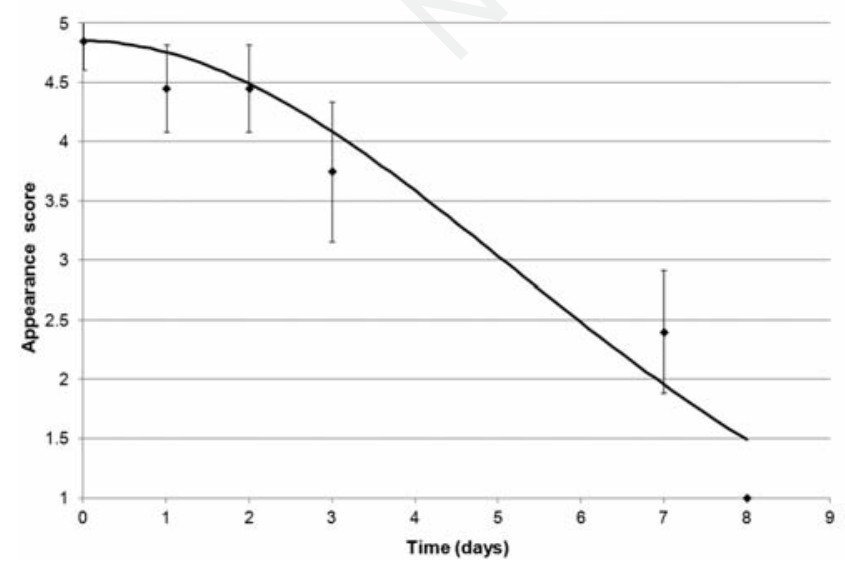

Figure 1. Changes in appearance score in melon sample as a function of time. $(\diamond)$ Experimental data (mean scores with $n=1.967$; bars indicate standard deviation values). Solid line shows Weibull model.

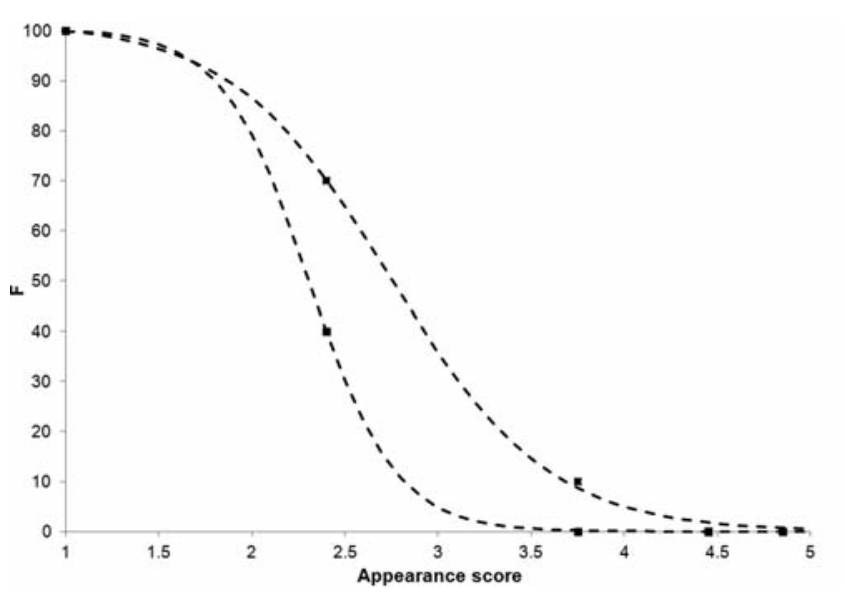

Figure 2. Correlation between fraction of not-marketable and inedible (F) samples and the average appearance score. ( $\bullet$ Curve of marketability; (-) curve of edibility. Dashed lines show logistical model. 
Figure 3 reports the experimental value of vitamin $\mathrm{C}$ content of melon samples over time as well as the curve fitted using the Weibull model. The estimated scale and shape factors were 17.09 and 0.629 , respectively, indicating the different trend in vitamin $\mathrm{C}$ degradation in comparison with appearance score. Fresh samples showed a vitamin $\mathrm{C}$ content of $17.93 \pm 3.78 \mathrm{mg} / 100 \mathrm{~g}$ that was in accordance with the content of $20 \mathrm{mg} / 100 \mathrm{~g}$ reported for whole cantaloupes by Gil et al. (2006). However, during storage, vitamin $\mathrm{C}$ showed a fractional decrease, losing $46.43 \%(9.60 \pm 2.30 \mathrm{mg} / 100)$ of their initial content at eight days of storage at $5^{\circ} \mathrm{C}$. Moreover, since the inverse of the scale factor of the Weibull has rate units, it was possible to calculate a rate constant of $0.0581 \mathrm{~d}^{-1}$ for the degradation of vitamin $\mathrm{C}$ in cut melons. Similar results were obtained from Oms-Oliu et al. (2009) who modelled the vitamin $\mathrm{C}$ degradation with the Weibull model and reported a rate constant of $0.019 \mathrm{~d}^{-1}$ for watermelon samples stored at $5^{\circ} \mathrm{C}$. Finally, in order to analyse at the same time the chemical and sensorial changes and to predict shelf life of fresh-cut melon samples, the estimated values obtained from the Weibull model were normalised by calculating the value of $\mathrm{C}_{\mathrm{i}} / \mathrm{C}_{0}$, where $\mathrm{C}_{\mathrm{i}}$ is the value of the considered index at time $i$, and $\mathrm{C}_{0}$ is the value of fresh samples (Figure 4). It is interesting to observe a slight decrease after one day in appearance and translucency scores (in fact, they maintained an approx. $98 \%$ of their initial value), whereas firmness, aroma and vitamin $\mathrm{C}$ showed higher degradations levels with $93.3 \%, 87.5 \%$, and $84.5 \%$, respectively, of their initial values. Also, in accordance with van Boekel (2002), some interesting considerations can be made. In particular, due to the different shape factor values previously reported, it seems that aroma and vitamin $\mathrm{C}$ content reduced their degradation rate with storage time, while translucency and appearance scores and firmness degradation rates increased as a function of time. On the basis of this, after three days of storage, appearance score and translucency score maintained a value of $84.24 \%$ and $88.25 \%$, respectively, whereas aroma score, vitamin $\mathrm{C}$ and firmness showed a higher degradation with values of $73.38 \%, 71.55 \%$ and $76.21 \%$ of their initial values, respectively. Moreover, as reported above, when considering the limit of marketability (which corresponds to a fractional decrease in appearance score of 47.3\%), shelf life can be estimated at five days at which translucency and aroma scores were estimated at 3.87 and 2.27 , respectively, showing that the aroma was judged to be poor and with major defect. On the other hand, after five days, a vitamin $\mathrm{C}$ content of $11.30 \mathrm{mg} / 100 \mathrm{~g}$ and a firmness of $16.5 \mathrm{~N}$ were estimated. In particular, the relative decrease in vitamin $\mathrm{C}$ content and firmness were $37 \%$ and $40 \%$, respectively, indicating that, even if the rates of the degradation reactions differed, there was a substantial loss of vitamin $\mathrm{C}$ and, above all, of firmness and aroma, which can be defined

Table 4. Weibull model parameters for sensorial and chemical attribute changes in melon samples stored at $5^{\circ} \mathrm{C}$ for 8 days.

\begin{tabular}{lcccc} 
Quality attribute & Parameters & $\begin{array}{c}\text { Estimates } \\
\text { Appearance score }\end{array}$ & $\begin{array}{c}\text { Confidence interval } \\
\text { (low) }\end{array}$ & $\begin{array}{c}\text { Confidence interval }^{*} \\
\text { (high) }^{*}\end{array}$ \\
Aroma score & $\alpha^{\circ}$ & 7.354 & 5.093 & 9.614 \\
& $\beta^{\#}$ & 1.967 & 0.5007 & 4.435 \\
Translucency score & $\alpha$ & 13.78 & -0.4487 & 28.01 \\
& $\beta$ & 0.7694 & -0.1142 & 1.653 \\
Firmness & $\alpha$ & 12.52 & 7.935 & 17.11 \\
& $\beta$ & 1.456 & 0.4065 & 2.506 \\
Vitamin C & $\alpha$ & 8.575 & 7.163 & 9.987 \\
& $\beta$ & 1.241 & 0.8938 & 1.589 \\
\hline
\end{tabular}

${ }^{*}$ Confidence intervals were computed at $95 \%$ of probability; ${ }^{\circ}$ scale factor (in days); ${ }^{\sharp}$ shape factor (dimensionless).

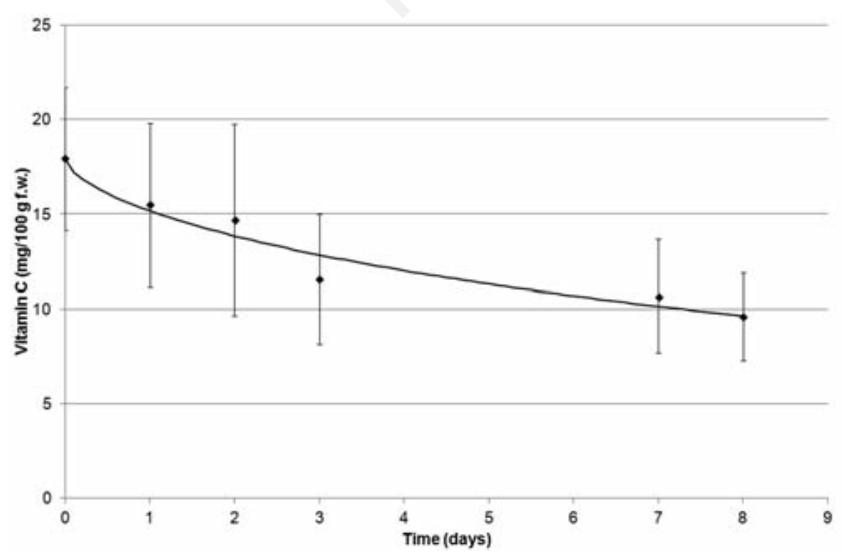

Figure 3. Vitamin $\mathrm{C}$ content of fresh-cut melon samples as a function of time. ( ) Experimental data. Solid line shows fit obtained by Weibull model.

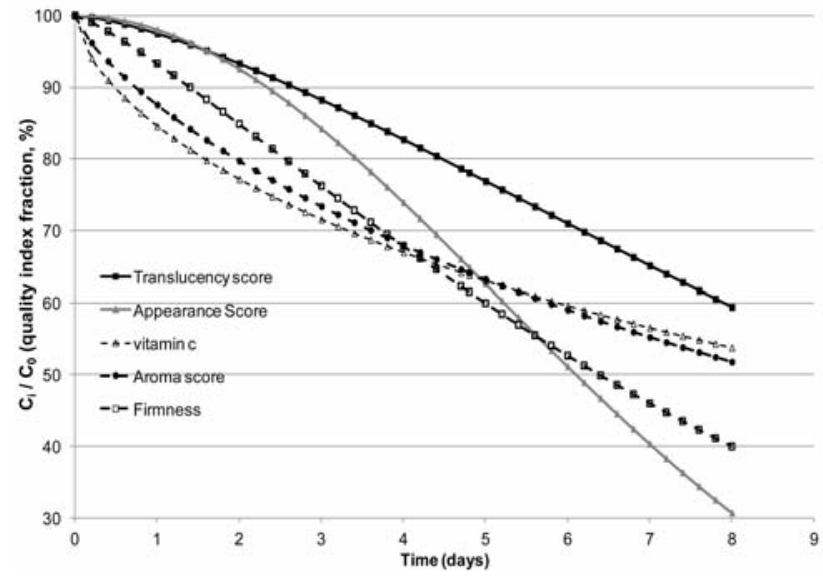

Figure 4. Time evolution of some sensorial and chemical changes of fresh-cut melon samples during storage in refrigerated conditions. 
as the most critical factors. Moreover, taking into account the limit of edibility (mean appearance score 2) which was reached after 6.8 days of storage, translucency and aroma score were estimated at 3.31 and 2.01 , respectively, whereas vitamin $\mathrm{C}$ content and firmness were estimated at $10.24 \mathrm{mg} / 100 \mathrm{~g}$ and $13.05 \mathrm{~N}$, respectively. If we analyse the results in terms of nutritional value of the fresh-cut melon samples, the recommended daily intake (RDI) of vitamin $\mathrm{C}$ ranges between 40 and $60 \mathrm{mg}$ (Australia and New Zealand Food Authority, 2001; UK Ministry of Agricultural, 2005; US FDA, 1998). Considering a nominal weight of 100 $\mathrm{g}$ of fruit inside each package, and considering a minimum intake of 40 $\mathrm{mg}$, it is possible to calculate that, at the start of storage, fresh-cut melon samples could provide $44.8 \pm 0.1 \%$ of the RDI of vitamin C, whereas consuming the same melons at the end of their shelf-life (5 days), the intake of vitamin C would only be $28 \%$ of the RDI.

\section{Conclusions}

The Weibull model fitted sensorial and chemical changes of freshcut melons better than conventional zero and first order models. According to this model, the limits of marketability and edibility of fresh-cut melon based on appearance score were estimated at 5 and 6.9 days, respectively, of storage. Moreover, the use of a logistical (sigmoidal) model allowed us to fit the fraction of packages judged as nonmarketable and non-edible with exceptional accuracy as a function of the average appearance scores. In this way, it was possible to confirm that when the average appearance score reached the limit of marketability, $35.8 \%$ of the packages were already below this limit. Moreover, from these results it was possible to understand that at the marketability limit, loss of aroma was more critical than appearance change, and that a substantial loss in vitamin $\mathrm{C}$ should be taken into account if shelf life is to be estimated only on the basis of external appearance. This information should be used to optimise the logistical chain with the aim of increasing the quality of fresh-cut melons on the market while also reducing the related costs.

\section{References}

Amaro A.L., Beaulieu J.C., Grimm C.C., Stein R.E., Almeida D.P.F. 2012. Effect of oxygen on aroma volatiles and quality of fresh-cut cantaloupe and honeydew melons. Food Chem. 130:49-57.

Ames B.M. 1983. Dietary carcinogens and anticarcinogens; oxygen radicals and degenerative diseases. Science. 221:1256-63.

Amodio M.L., Cabezas A., Rinaldi R., Colelli G. 2007. Implementation of rating scale for visual quality evaluation of various vegetables. Appendix 1. In: A.A. Kader and M. Cantwell (eds.), Produce quality rating scales and color charts. Postharvest Horticoulture Series No. 23, Univ. of California, Davis, CA, USA.

Amodio M.L., Dollo L., Rinaldi R., Colelli G. 2012. Degradation patterns for external and nutritional quality parameters of fresh-cut "Cantaloupe" melons. Acta Hort. 934:641-8.

Ares G., Martinez I., Lareo C., Lema P. 2008. Failure criteria based on consumers' rejection to determin the sensory shelf life of minimally processed lettuce. Post Biol. Technol. 49:255-9.

Australia and New Zealand Food Authority (ANZFA). 2001. Australian food standards code. Australian Government Publishing Service, Canberra, Australia.

Bett K.L., Ingram D.A., Grimm C.C., Lloyd S.W., Spanier A.M., Miller J.M. Gross K.C., Baldwin E.A., Vinyard B.T. 2001. Flavor of freshcut gala apples in barrier film packaging as affected by storage time. J. Food Qual. 24:141-56.

Brand-Williams W., Cuvelier M.E., Berset C. 1995. Use of a free radical method to evaluate antioxidant activity. Food Sci. Technol. 28:2530 .

Brecht J.K. 1995. Physiology of lightly processed fruits and vegetables. Hort. Sci. 30:18-22.

Corradini M.G., Normand M.D., Peleg M. 2005. Generating microbial survival curves during thermal processing in real time. J. Appl. Microbiol. 98:406-17.

Corradini M.G., Peleg M. 2004a. A model of non-isothermal degradation of nutrients, pigments and enzymes. J. Food. Sci. Agric. 84:217-26.

Corradini M.G., Peleg M. 2004b. Demostration of the Weibull-Log logistic survival model's applicability to non isothermal inactivation of E. coli k12 MG1655. J. Food Prot. 67:2617-21.

Corradini M.G., Peleg M. 2006. Prediction of vitamins loss during nonisothermal heat processes and storage with non-linear kinetic models. Trends Food Sci. Tech. 17:24-34.

Corradini M.G., Peleg M. 2007. Shelf life estimation from accelerated storage data. Trends Food Sci. Tech. 18:37-47.

Cunha L.M., Oliveira A.R., Aboim A.P., Frias J.M., Pinheiro-Torres A. 2001. Stochastic approach to the modelling of water losses during osmotic dehydration and improved parameter estimation. Int. J. Food Sci. Tech. 36:253-62.

Dabbene F., Gay P., Sacco N. 2008. Optimisation of fresh-food supply chains in uncertain environments, Part I: Background and methodology. Bio. Eng. 99:348-59.

Davey M.W., Van Montagu M., Inze D., Sanmartin M., Kanellis A., Smirnoff N., Benzie I.J.J., Strain J.J., Favell D., Fletcher J. 2000. Plant L-ascorbic: chemistry, function, metabolism, bioavailable and effects of processing. J. Food Sci. Agric. 80:825-60.

Giannakourou M.C., Taoukis P.S. 2003. Kinetic modelling of vitamin C loss in frozen green vegetables under storage conditions. Food Chem. 83:33-41.

Gil M.I., Aguayo E., Kader A.A. 2006. Quality changes and nutrient retention in fresh-cut versus whole fruits during storage. J. Agric. Food Chem. 54:4284-96.

Jacxsens L., Luning P.A., van der Vorst J.G.A.J., Devlieghere F., Leemans R., Uyttebdaele M. 2010. Simulation modelling and risk assessment as tools to identify the impact of climate change on microbiological food safety - The case study of fresh produce supply chain. Food Res. Int. 43:1925-35.

Klein B.P. 1987. Nutritional consequence of minimal processing of fruits and vegetables. J. Food Qual. 10:179-93.

Labuza T.P. 1982. Open shelf life dating of foods. Food and Nutrition Press, Westport, CT, USA.

Manso M.C., Oliveira F.A.R., J.C. Frias J.M. 2001. Modelling ascorbic acid thermal degradation and browning in orange juice under aerobic conditions. Int. J. Food Sci. Tech. 36:303-12.

Marabi A., Livings S., Jacobson M., Saguy I.S. 2003. Normalized Weibull distribution for modeling rehydration of foods particulates. Eur. Food Res. Technol. 217:311-8.

Martin A., Cherubini A., Andres-Lacueva C., Paniagua M., Joseph J.A. 2002. Effects of fruits and vegetables on levels of vitaimns $E$ and $C$ in the brain and their association with cognitive performance. J. Nutr. Health Aging. 6:392-404.

Nisha P., Singhal R.S., Pandit A.B. 2005. A study on degradation kinetics of riboflavin in spinach (Spinacea oleracea L.). J. Food Eng. 67:40712.

Odriozola-Serrano I., Soliva-Fortuny R., Martin-Belloso 0. 2009. Influence of storage temperature on the kinetics of the changes in anthocyanins, vitamin c, and antioxidant capacity in fresh-cut strawberries stored under high-oxygen atmospheres. J. Food Sci. 74:184-91. 
Oms-Oliu G., Odriozola-Serrano I., Soliva-Fortuny R., Martin-Belloso 0. 2009. Use of Weibull distribution for describing kinetics of antioxidant potential changes in fresh-cut watermeon. J. Food Eng. 95:99-105.

Peleg M. 1988. An empirical model for the description of moisture sorption curves. J. Food Eng. 55:1084-7.

Polydera A.C., Stoforos N.G., Taoukis P.S. 2005. Quality degradation kinetics of psteurised and high pressure processed fresh navel orange juice: nutritional parameters and shelf-life. Innov. Food Sci. Emerg. 85: 591-8.

Rekha Nisha P., Singhal S., Pandit A.B. 2004. A study on degradation kinetics of thiamine in red gram splits. Food Chem. 85:591-8.

Rodrigo D., van Loey A., Hendrickx M. 2007. Combined thermal and high pressure colour degradation of tomato puree and strawberry juice. J. Food Eng. 79:553-60.

Sáiz-Abajo M.J., González-Sáiz J.M., Pizarro C. 2005. Multi-objective optimisation strategy based on desirability functions used for chromatographic separation and quantification of l-proline and organic acids in vinegar. Anal. Chim. Acta. 528:63-76.

Singleton V.L., Rossi J.A. 1965. Caolorimetry of total phenolic with phosphomolybdic-phosphotungstic acid reagents. Am. J. Enol. Vitic. $16: 144-58$.

Sothornvit R., Kiatchanapaibul P. 2009. Quality and shelf life of washed fresh-cut asparagus in modified atmosphere packaging.
Food Sci. Technol. 42;1484-90.

Tauokis P., Labuza T.P., Saguy I.S. 1997. Kinetics of food deterioration and shelf life prediction. In: K.J. Valentas, E. Rostein, R.P. Singh (eds.), Handobook of food engineering practice. CRC Press, Boca Raton, FL, USA.

UK Ministry of Agriculture. 1995. The British nutrition foundation: brieging paper on food processing and dietary reference values. In: UK Ministry of Agriculture - Fisheries and Food, The manual of nutrition. $10^{\text {th }}$ ed. Her Majesty's Stationery Office (HMSO), London, UK.

US FDA (Food and Drugs Administration). 1998. FDA nutritional labeling manual: A guide for developing and using databases. Center for Food Safety and applied Nutrition, Washington, DC, USA.

Vamos-Vigyazo L. 1981. Polhyphenol oxidase and peroxidase in fruits and vegetables. Crit. Rev. Food Sci. 15:49-127.

van Boekel M.A.J.S. 2002. On the use of weibull model to describe thermal inactivation of microbial vegetative cells. Int. J. Food. Microbiol. 74:139-59.

Zanoni B., Pagliarini E., Galli A., Laureati M. 2005. Shelf-life prediction of fresh blood orange juice. J. Food Eng. 70:512-7.

Zapata S., Dofour J.P. 1992. Ascorbic, dehydroascorbic and isoascorbic acid simultaneous determinations by reverse phase ion interaction HPLC. J. Food Sci. 57:506-11. 